\title{
Primary Extracranial Meningiomas: An Analysis of 146 Cases
}

\author{
Elisabeth J. Rushing · John-Paul Bouffard • \\ Sherman McCall · Cara Olsen · Hernando Mena • \\ Glenn D. Sandberg · Lester D. R. Thompson
}

Received: 6 March 2009/Accepted: 11 April 2009/Published online: 20 May 2009

(C) The Author(s) 2009. This article is published with open access at Springerlink.com

\begin{abstract}
Primary extracranial meningiomas are rare neoplasms, frequently misdiagnosed, resulting in inappropriate clinical management. To date, a large clinicopathologic study has not been reported. One hundred and forty-six cases diagnosed between 1970 and 1999 were retrieved from the files of the Armed Forces Institute of Pathology. Histologic features were reviewed, immunohistochemistry analysis was performed $(n=85)$, and patient follow-up was obtained $(n=110)$. The patients included $74(50.7 \%)$ females and $72(49.3 \%)$ males. Tumors of the skin were much more common in males than females (1.7:1). There was an overall mean age at presentation of 42.4 years, with a range of $0.3-88$ years. The overall mean age at presentation was significantly younger for skin primaries (36.2 years) than for ear (50.1 years) and nasal cavity (47.1 years) primaries. Symptoms were in general non-specific and reflected the anatomic site of involvement, affecting the following areas in order of frequency: scalp skin (40.4\%), ear and temporal bone (26\%), and sinonasal
\end{abstract}

E. J. Rushing $(\bowtie) \cdot$ J.-P. Bouffard · H. Mena · G. D. Sandberg Department of Neuropathology and Ophthalmic Pathology, Armed Forces Institute of Pathology, Washington, DC 20306-6000, USA

e-mail: rushinge@afip.osd.mil; elisabeth.rushing@gmail.com

S. McCall

Department of Molecular Pathology, Armed Forces Institute of Pathology, Washington, DC, USA

C. Olsen

Department of Preventive Medicine and Biometrics, Uniformed University of the Health Sciences, Bethesda, MD, USA

L. D. R. Thompson

Department of Pathology, Southern California Permanente

Medical Group, Los Angeles, CA, USA

e-mail: lester.thompson@headandneckpathologyjournal.com tract (24\%). The tumors ranged in size from 0.5 up to $8 \mathrm{~cm}$, with a mean size of $2.3 \mathrm{~cm}$. Histologically, the majority of tumors were meningothelial $(77.4 \%)$, followed by atypical (7.5\%), psammomatous (4.1\%) and anaplastic (2.7\%). Psammoma bodies were present in 45 tumors (30.8\%), and bone invasion in $31(21.2 \%)$ of tumors. The vast majority were WHO Grade I tumors (87.7\%), followed by Grade II (9.6\%) and Grade III (2.7\%) tumors. Immunohistochemically, the tumor cells labeled for EMA (76\%; 61/80), S-100 protein $(19 \% ; 15 / 78)$, CK $7(22 \% ; 12 / 55)$, and while there was ki-67 labeling in $27 \%(21 / 78),<3 \%$ of cells were positive. The differential diagnosis included a number of mesenchymal and epithelial tumors (paraganglioma, schwannoma, carcinoma, melanoma, neuroendocrine adenoma of the middle ear), depending on the anatomic site of involvement. Treatment and follow-up was available in 110 patients: Biopsy, local excision, or wide excision was employed. Follow-up time ranged from 1 month to 32 years, with an average of 14.5 years. Recurrences were noted in 26 (23.6\%) patients, who were further managed by additional surgery. At last follow-up, recurrent disease was persistent in 15 patients (mean, 7.7 years): 13 patients were dead (died with disease) and two were alive; the remaining patients were disease free (alive 60, mean 19.0 years, dead 35 , mean 9.6 years). There is no statistically significant difference in 5-year survival rates by site: ear and temporal bone: $83.3 \%$; nasal cavity: $81.8 \%$; scalp skin: $78.5 \%$; other sites: $65.5 \%(P=0.155)$. Meningiomas can present in a wide variety of sites, especially within the head and neck region. They behave as slow-growing neoplasms with a good prognosis, with longest survival associated with younger age, and complete resection. Awareness of this diagnosis in an unexpected location will help to avoid potential difficulties associated with the diagnosis and management of these tumors. 
Keywords Meningioma - Extracranial . Immunohistochemistry · Prognosis · Radiation · WHO classification

\section{Introduction}

Meningioma is a well-recognized tumor of the central nervous system (CNS) that typically arises in proximity to the meninges. These neoplasms are more common in females during the middle decades of life and account for 24-30\% of primary intracranial tumors [1]. Most commonly extra-neuraxial, meningiomas are found overlying the surface of the brain or at the skull base [2]. Uncommonly, meningiomas occur in intraventricular [3, 4], intraparenchymal $[2,5]$, or intraosseous locations. In rare instances $(<2 \%)$, they appear as an extracranial tumor, most often in the head and neck region [2-20], and specifically in the sinonasal tract [20], ear and temporal bone [19], and scalp [21]. The histopathologic diagnosis is usually straightforward; however, the diagnosis may pose challenges in these unexpected locations where the differential diagnosis includes paraganglioma, carcinoma, melanoma, schwannoma, and olfactory neuroblastoma, among others. Previous reports on meningioma in uncommon locations are largely limited to individual cases or small series $[2,4-10,12-16]$. The objective of this retrospective study is to present our experience, the largest series to date, with extracranial meningiomas, highlighting clinicopathologic features and outcome associated with the surgical treatment of these tumors.

\section{Materials and Methods}

\section{Study Population}

The records of 205 patients with primary extracranial meningiomas were retrieved from the registries of the Otorhinolaryngic-Head and Neck Tumor Registry, Soft Tissue Registry and the Neuropathology Registry of the Armed Forces Institute of Pathology (AFIP) between the years 1970 and 1999. The anatomic sites included ear, temporal bone, sinonasal tract (including paranasal sinuses), scalp, chest and thorax, pelvis and extremities. However, 59 patients were excluded from further consideration because of at least one of the following reasons: (1) paraffin blocks were unavailable for additional sections; (2) the original submitted case did not have sufficient demographic information supplied to warrant inclusion or from which to obtain adequate follow-up information; (3) patients with primary tumors of the intracranial cavity, who later developed extra-cranial manifestations were excluded; (4) the cases were diagnosed indefinitely, using terms such as "consistent with," "suggestive of," or "suspicious for." The remaining 146 patients with meningioma compose the subject of this study based upon adequate clinical information, demographic findings, and materials for follow-up and hematoxylin and eosin-stained slides to make a definitive diagnosis.

Materials within the files of the AFIP were supplemented by a review of the patient demographics, medical history, surgical pathology and operative reports, oncology data services, cancer registry records, and by written questionnaires or oral communication with the treating physician(s). Follow-up data tabulated included information regarding the location of the primary site, the specific treatment modalities used, and the current status of the disease and patient. Extent of resection was defined as partial (P) or gross total resection (GTR) based on information coded at the treating institution. This clinical investigation was conducted in accordance and compliance with all statutes, directives, and guidelines of the Code of Federal Regulations, Title 45, Part 46, and the Department of Defense Directive 3216.2 relating to human subjects in research.

\section{Pathological Investigation}

The macroscopic pathology observations noted within this study were gathered from the individual gross descriptions of the neoplasms given by the contributing pathologists. In all cases, tumor tissue consisted of formalin fixed, routinely processed, and paraffin embedded surgical specimens. Hematoxylin and eosin-stained slides from all cases were reviewed to confirm the diagnosis of meningioma by all four neuropathologists (EJR, JPB, GDS, and HM) and an otorhinolaryngic pathologist (LDRT), independently initially, and followed by a consensus conference for any case that raised a diagnostic differential consideration or was a Grade II or Grade III tumor. Meningiomas were assessed and classified according the World Health Organization 2000 and 2007 [1, 22]. Mitoses were counted by examining 10 high power fields (HPF) for each tumor in the region of highest cellularity and determining an average number per 10 HPF. Lesions were considered atypical if they possessed a mitotic rate greater than four per 10 high-power fields $\left(2.5 \mathrm{~mm}^{2}\right)$ $[23,24]$ and/or had at least three of the following histologic features: hypercellularity, growth of tumor cells in sheets, prominent nucleoli, necrosis, and small cell formation $[1,22]$.

Immunophenotypic analysis was performed in 80 cases using the standardized avidin-biotin method, using $4 \mu \mathrm{m}$ thick, formalin- fixed, paraffin-embedded sections. Table 1 documents the pertinent, commercially available 
immunohistochemical antibody panel used. The analysis was performed on a single representative block in each case. When required, proteolytic antigen retrieval was performed with predigestion for 3 min with $0.05 \%$ Protease VIII (Sigma Chemical Co, St. Louis, MO, USA) in a $0.1 \mathrm{M}$ phosphate buffer at a $\mathrm{pH}$ of 7.8 at $37^{\circ} \mathrm{C}$. Antigen enhancement (recovery) was performed, as required, using formalin-fixed, paraffin-embedded tissue treated with a buffered citric acid solution and heated for 20 min in a calibrated microwave oven. Following this, the sections were allowed to cool at room temperature in a citric acid buffer solution for $45 \mathrm{~min}$ before continuing the procedure. Standard positive and negative (serum) controls were used throughout. The antibody reactions were graded as weak $(1+)$, moderate $(2+)$, and strong (3+) staining, and the fraction of positive cells was determined by separating the percentage of positive cells into four groups: $<10 \%, 10$ $50 \%, 51-90 \%$, and $>90 \%$. To quantify the percentage of nuclei staining with $\mathrm{Ki}-67$, at least 500 tumor cells were manually counted; three separate counts were performed in the region of tumor with highest nuclear staining, and an average percentage of positively stained nuclei was calculated.

A review of publications in English (MEDLINE 19662008) was performed, and all cases primarily involving the ear and temporal bone, skin, orbit, oral cavity, nasal cavity, nasopharynx, paranasal sinuses, soft tissues, and solid organs (lung, liver, spleen) and hollow organs (colon, bladder, uterus, stomach) were included in the review. Cases of cranial cavity or spinal canal meningiomas which metastasized to distant sites were not included in the review, unless they involved the sites described above. Non-English articles were not included.
Statistics

Survival probabilities were calculated according to the Kaplan-Meier method and were measured from the date of diagnosis until the date of last follow-up or until death. Bivariate associations between survival and prognostic factors were tested using the log-rank test. Multivariate associations between survival and prognostic factors were tested using the Cox proportional hazards regression. Categorical variables were analyzed using Chi-square tests to compare observed and expected frequency distributions. Comparison of means between groups were made with unpaired $t$ tests. Confidence intervals of $95 \%$ were generated for all positive findings. The alpha level was set at $P<0.05$. Statistical analysis was performed using SPSS version 12.0 for Windows (SPSS, San Diego, CA) and STATA version 8.1 for Windows (Stata Corporation, College Station, TX). Often the date of last follow-up was given as month and year, but no day was available. In those cases, follow-up was calculated to the 15th day of the month.

\section{Results}

\section{Clinical}

The patients included 74 females and 72 males (Table 2). There was a statistically significant gender difference based on anatomic site $(P=0.044)$, with a greater number of men among patients with scalp skin lesions (63\%) and a greater number of women among ear lesions (66\%). Patients' age at presentation ranged from 3 months to

Table 1 Immunohistochemistry panel

\begin{tabular}{lllll}
\hline Antigen/antibody & Primary antibody & Company & Dilution & Antigen recovery \\
\hline Vimentin & $\mathrm{rp}$ & Dako, Carpinteria, CA & $1: 200$ & $\mathrm{n} / \mathrm{a}$ \\
Epithelial membrane antigen (EMA) & $\mathrm{mm}$ & Dako & $1: 100$ & Protease digestion \\
Cytokeratin (AE1/AE3 and CK1) & $\mathrm{mm}$ & Boehringer Mannheim Biochemicals, & $1: 50$ & Protease treatment \\
& & Indianapolis, IN, and Dako & $1: 200$ & $1: 200$ \\
CK7 & $\mathrm{mm}$ & Dako & $1: 800$ & Protease digestion \\
S-100 protein & $\mathrm{rp}$ & Dako & $1: 100$ & Protease digestion \\
CAM5.2 & $\mathrm{mm}$ & Ventana, Tucson, AZ & Neat & Protease digestion \\
Synaptophysin & $\mathrm{rp}$ & Dako & $1: 50$ & Protease digestion \\
CK20 & $\mathrm{mm}$ & Dako & $1: 2000$ & Protease digestion \\
Glial fibrillary acidic protein (GFAP) & $\mathrm{rp}$ & Dako & $1: 100$ & $\mathrm{n} / \mathrm{a}$ \\
Chromogranin & $\mathrm{mm}$ & Dako & $1: 80$ & Microwave \\
Synuclein & $\mathrm{mm}$ & Novacastra, New Castle, UK & $1: 20$ & Microwave \\
Ki67 & $\mathrm{mm}$ & Immunotech, Westbrook, ME & &
\end{tabular}

$m m$ mouse monoclonal, $r p$ rabbit polyclonal 
Table 2 Clinical characteristic of 146 extracranial meningiomas

\begin{tabular}{|c|c|}
\hline Clinical characteristics & $N=146$ \\
\hline \multicolumn{2}{|l|}{ Gender } \\
\hline Females & 74 \\
\hline Ear and temporal bone & 25 \\
\hline Nasal cavity and nasopharynx & 19 \\
\hline Other (soft tissue, neck) & 8 \\
\hline Skin—scalp & 22 \\
\hline Males & 72 \\
\hline Ear and temporal bone & 13 \\
\hline Nasal cavity and nasopharynx & 16 \\
\hline Other (soft tissue, neck) & 6 \\
\hline Skin—scalp & 37 \\
\hline \multicolumn{2}{|l|}{ Age (in years) } \\
\hline Range & $0.25-88$ \\
\hline Ear and temporal bone & $10-80$ \\
\hline Nasal cavity and nasopharynx & $4-88$ \\
\hline Other (soft tissue, neck) & $9-71$ \\
\hline Skin—scalp & $0.3-84$ \\
\hline Mean & 42.4 \\
\hline Females & 45.6 \\
\hline Males & 39.6 \\
\hline Ear and Temporal bone & 50.1 \\
\hline Females & 51.6 \\
\hline Males & 47.2 \\
\hline Nasal cavity and nasopharynx & 47.1 \\
\hline Females & 51.4 \\
\hline Males & 42.1 \\
\hline Other (soft tissue, neck) & 35.6 \\
\hline Females & 31.0 \\
\hline Males & 42.0 \\
\hline Skin-scalp & 36.2 \\
\hline Females & 39.0 \\
\hline Males & 34.5 \\
\hline \multicolumn{2}{|l|}{ Symptom duration (in months) } \\
\hline Range & $0.5-240$ \\
\hline Mean & 27.1 \\
\hline Females (mean) & 27.0 \\
\hline Males (mean) & 27.3 \\
\hline
\end{tabular}

88 years of age, with an overall mean age at presentation of 42.4 years. The average age at presentation for women was older than men, at 45.6 and 39.6 years, respectively, but this difference did not reach statistical significance $(P=0.09)$; likewise, there was no statistical difference between genders when stratified for specific site (even though the average age for patients with nasal cavity tumors in males versus females was 42.1 versus 51.4 years). Ear and temporal bone tumors had an older mean age at presentation when compared to scalp skin and other soft tissue lesions: 50.1 versus 36.2 years $(P=0.004)$ and 35.6 years $(P=0.042)$, respectively. A possible explanation may be entrapped meningeal tissue during embryologic development, which undergoes neoplastic transformation and comes to clinical attention before an intraosseous lesion.

Patients symptoms were referable to the anatomic site of tumor involvement. Skin scalp lesions and neck lesions presented with a mass. Tumors from the ear and temporal bone presented with hearing changes, either sensorineural or conductive hearing loss, otitis, headaches, dizziness, unsteadiness, vertigo, disequilibrium, tinnitus, otalgia, and bleeding. Facial nerve or other cranial nerves were involved in 4 patients. Patients with tumors arising in the nasal cavity presented with a mass lesion, epistaxis, sinusitis, pain, and/or obstructive symptoms. Four patients in this group also had visual changes, including blindness, possibly related to pressure effect from the mass as it expanded in size, although the blindness did not resolve after the tumors were removed. None of the patients in this series were asymptomatic, although sometimes the "skin nodule" or "tumor" was not clinically worrisome to the patient and may have been an incidental finding during examination for a different reason. Although not available in all patients, when questioned, no patients reported being part of a kindred with von Recklinghausen's disease or any other phakomatosis.

The duration of symptoms ranged from 2 weeks to 240 months, with an average of 27.1 months. The overall long duration of symptoms is most likely related to the generally nonspecific nature of the initial symptoms, and patients were frequently managed without a specific diagnosis. There was no difference in average symptom duration between the genders (female 27.0 months, male 27.3 months). When contiguous adjacent anatomic sites were involved, the symptom duration was generally shorter than patients whose tumor involved a single site: ear and temporal bone sites: 7.6 months; nasal cavity and paranasal sinuses: 31.3 months versus external auditory canal: 47.3 months and nasal cavity alone: 36.5 months.

Radiographic procedures were performed in the majority of patients with ear and temporal bone and nasal cavity lesions, but generally not performed in the evaluation of skin and soft tissue cases. In general, by computed tomography scans, a mass was identified, sometimes interpreted to represent an infectious or inflammatory condition. Generally, bony destruction was not identified, although displacement, sclerosis or remodeling was seen, especially in the sinonasal cavity cases. Specifically, a central nervous system (CNS) connection was generally not identified in the majority of patients where tests had been performed (81.4\%), especially in the patients who had radiographic studies interpreted as normal (40\%). 
However, in a few cases $(n=9)$, bone erosion with extension of the tumor into the base of the skull was noted. Still, the tumor bulk was extraneuraxial. Magnetic resonance with a T1-weighted, gadolinium diethylene triamine pentoacetic acid (Gd-DTPA) enhancement helped underscore the nature of the lesion and the extent of the tumor.

Pathologic Features

\section{Macroscopic}

The vast majority of tumors affected the skin of the scalp (Table 3). There was no particular predilection anatomically, with forehead, vertex, occipital, frontal, parietal and temporal locations stated. It would be difficult to extrapolate association with the cranial bone suture lines, but some of the tumors were probably overlying these landmarks.

The ear and temporal bone tumors occurred in the middle ear alone $(n=26)$, external auditory canal only $(n=4)$, temporal bone only $(n=2)$, and involving the temporal bone, middle ear, external auditory canal and eustachian tube combined $(n=6)$. Tumors were unilateral. The tumors ranged in size from 0.5 to $4.5 \mathrm{~cm}$, with a mean size of $1.2 \mathrm{~cm}$. There was a statistically significantly larger size for tumors which arose in the temporal bone (mean $2.8 \mathrm{~cm}$ ), as opposed to the external auditory canal (mean $1.1 \mathrm{~cm})$, middle ear $($ mean $1.1 \mathrm{~cm})$, or mixed $(1.2 \mathrm{~cm})$ $(P=0.02)$.

Table 3 Macroscopic findings of 146 extracranial meningiomas

Extracranial meningiomas

Anatomic site

Skin—scalp

59

Middle ear

26

Nasal cavity alone

17

Nasal cavity and paranasal sinuses

Ear and temporal bone (mixed)

Nasopharynx alone

External auditory canal

Neck

Intra-abdominal/pelvis

Sinus alone (frontal, ethmoid, sphenoid) 5

Soft tissues

Orbit

Temporal bone

Mandible

Parotid gland

Extension into eustachian tube

Size (in $\mathrm{cm}$ )

Range

Mean
The sinonasal tract tumors occurred in the nasal cavity alone $(n=17)$, nasopharynx alone $(n=5)$, frontal or ethmoid sinus alone $(n=3)$, sphenoid sinus alone $(n=2)$, and in the nasal cavity and the paranasal sinuses $(n=8)$, including ethmoid, frontal, sphenoid, and/or maxillary sinus (Table 3). Five patients presented with bilateral nasal cavity disease. The tumors ranged in size from 1.0 to $8.0 \mathrm{~cm}$, with a mean size of $3.5 \mathrm{~cm}$.

The other anatomic sites included the neck $(n=4)$, pelvic bones or intra-abdominal cavity $(n=3)$, soft tissues of the back and Achilles tendon $(n=3)$, orbit $(n=2)$, mandible $(n=1)$ and parotid gland $(n=1)$. Specific information about the size of the lesion was not available in these soft tissue locations.

The cut surface, when not submitted in multiple fragments, was composed of grayish white-tan to pink, gritty, firm to rubbery masses. The ear, temporal bone, and sinonasal tract tumors were often insinuated into bone, although the surface epithelium was intact (either squamous or respiratory, respectively). Calcifications were identified in the fragments of tissue, but may have included the bone rather than representing psammoma bodies.

\section{Microscopic}

The tumors were separated into a variety of histologic types and grades. Overall, there were 113 meningothelial (Fig. 1), 11 atypical, 6 psammomatous, 4 transitional, 4 anaplastic, 3 metaplastic, 2 clear cell, 2 fibrous, and 1 angiomatous meningioma(s). Overall, there were 128 WHO Grade I, 14 WHO Grade II, and 4 WHO Grade III tumors. By definition, atypical and clear cell types are WHO Grade II tumors, while anaplastic meningioma is

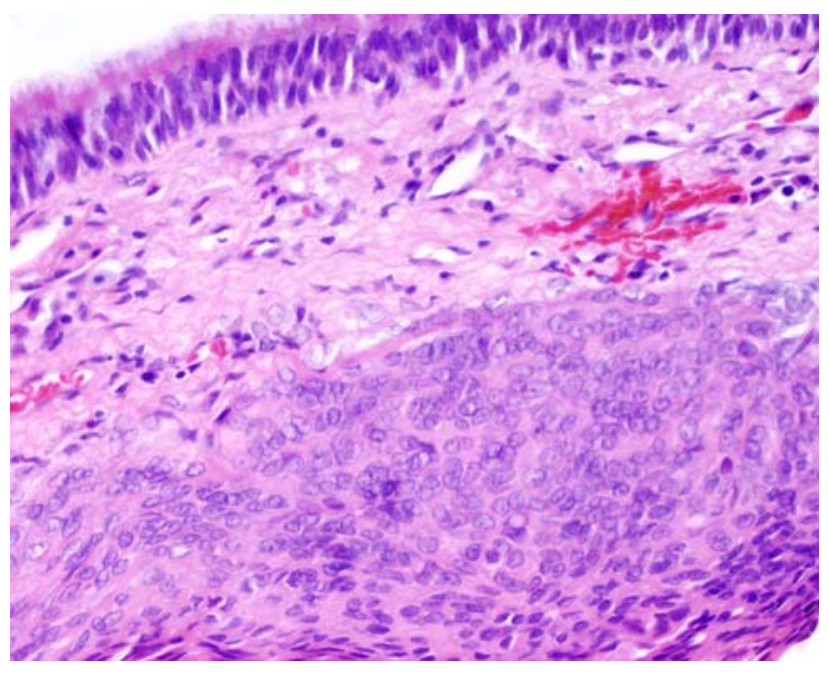

Fig. 1 Meningothelial meningioma from the left middle turbinate of a 40 year old male who presented with rhinorrhea and recurrent epitaxis 
WHO Grade III. These results are presented in tabular form based on anatomic site and as an overall percentage of each tumor type in each anatomic site (Table 4). In general, ear and temporal bone, scalp skin, and sinonasal tract tumors were meningothelial $(77.4 \%)$, with almost all $(95 \%)$ ear and temporal bone tumors within this category. Specific tumor types were as follows:

Atypical $(7.5 \%, n=5$ nasal cavity, $n=4$ soft tissues, $n=2$ scalp);

Psammomatous $(4.1 \%, n=2$ ear, $n=2$ scalp, $n=1$ back skin, $n=1$ neck);

Transitional $(2.7 \%, n=2$ nasal, $n=2$ scalp);

Anaplastic (2.7\%, $n=3 \mathrm{scalp}, n=1$ retroperitoneum);

Metaplastic (2.1\%, $n=2$ nasal, $n=1$ scalp);

Clear cell $(1.4 \%, n=1$ pelvis, $n=1 \mathrm{scalp})$;

Fibrous $(1.4 \%, n=2$ scalp); and

Angiomatous $(0.7 \%, n=1$ nasal) types.

In general, the tumors were composed of lobules and whorls of neoplastic epithelioid cells with indistinct borders. The nuclei were generally round to oval nuclei with delicate nuclear chromatin and occasional intranuclear pseudo-inclusions. Intranuclear inclusions were present in $71 \%$ of cases, although they were not always abundant or easy to find. Psammoma bodies were frequently identified $(n=45)$, although less frequently in the soft tissue and scalp tumors than in other tumor locations. The tumors often had an "infiltrative" appearance, extending into the adjacent tissues. These tissues may be soft tissue, skeletal muscle, or bone $(n=31)$. The bone was often remodeled, with islands of tumor infiltrating between the bony trabecular. However, the presence of "invasion" did not seem to correlate with patient outcome. For the non-skin primaries, the surface epithelium was intact, lacking ulceration or erosion, suggesting a slow growth rate. The other histologic types showed features unique to each entity:

(a) Fibrous spindle cell pattern with cells resembling fibroblasts in interlacing patterns with collagen;

(b) Transitional less well developed fascicles of fibroblast-like cells with more conspicuous whorling

(c) Angiomatous prominent vascular pattern within meningioma

(d) Psammomatous abundant psammoma bodies, often showing confluent calcifications;

(e) Metaplastic lipidized cells, xanthomatous or myxoid changes.

(f) Clear cell patternless proliferation of polygonal cells with cleared cytoplasm.

Atypical meningiomas have increased mitotic activity along with increased cellularity, small cells with high nuclear to cytoplasmic ratio, patternless or sheet-like
Table 4 Microscopic features of 146 extracranial meningiomas

Microscopic characteristic

Extracranial

meningiomas

Subtype

Meningothelial

$113(77.4 \%)$

Ear and temporal bone (36/38)

$94.7 \%$

Nasal cavity and nasopharynx (25/35)

$71.4 \%$

Other (soft tissue, neck) (6/14)

$42.9 \%$

Skin—scalp (46/59)

$78.0 \%$

Atypical

$11(7.5 \%)$

Ear and temporal bone $(0 / 38)$

Nasal cavity and nasopharynx (5/35)

0

Other (soft tissue, neck) (4/14)

$14.3 \%$

Skin—scalp (2/59)

$28.6 \%$

$3.4 \%$

Psammomatous

Ear and temporal bone (2/38)

$6(4.1 \%)$

$5.3 \%$

Nasal cavity and nasopharynx $(0 / 35)$

Other (soft tissue, neck) (2/14)

0

$14.3 \%$

Skin—scalp (2/59)

$3.4 \%$

Anaplastic

Ear and temporal bone (0/38)

Nasal cavity and nasopharynx $(0 / 35)$

Other (soft tissue, retroperitoneum) (1/14)

Skin—scalp (3/59)

$4(2.7 \%)$

0

0

$7.1 \%$

$5.1 \%$

$12(8.3 \%)$

Transitional, clear cell, fibrous, metaplastic, angiomatous

Ear and temporal bone $(0 / 38)$

0

Nasal cavity and nasopharynx (5/35)

Other (soft tissue, neck) (1/14)

$14.3 \%$

$7.1 \%$

Skin-scalp (6/59)

$10.2 \%$

Grade

I

Ear and temporal bone (38/38)

$128(87.7 \%)$

$100.0 \%$

$85.7 \%$

Nasal cavity and nasopharynx (30/35)

$57.1 \%$

Other (soft tissue, neck) (8/14)

$88.1 \%$

Skin-scalp (52/59)

$14(9.6 \%)$

II (includes atypical and clear cell type)

Ear and temporal bone (0/38)

Nasal cavity and nasopharynx (5/35)

0

$14.3 \%$

Other (soft tissue, neck) (5/14)

$35.7 \%$

Skin—scalp (4/59)

$6.8 \%$

III (anaplastic)

$4(2.7 \%)$

Ear and temporal bone (0/38)

Nasal cavity and nasopharynx $(0 / 35)$

Other (soft tissue, neck) (1/14)

0

0

Skin-scalp (3/59)

$7.1 \%$

$5.1 \%$

Bone invasion present

31

Psammoma bodies

45

Pseudoinclusions

104

Mitotic figures $>2 / 10 \mathrm{HPF}$

15

$H P F$ high power field 
growth, and geographic type necrosis. Nuclei with prominent nucleoli were also identified in these tumors. By definition, clear cell and chordoid meningiomas are Grade II.

Finally, four tumors showed profound pleomorphism, remarkably increased mitotic activity (mean, 24/10 HPF), and significant necrosis. These tumors developed in the retroperitoneum $(n=1)$, and scalp skin $(n=3)$. Two patients were lost to follow-up, one had died with local disease (3.4 years), and one patient was alive without evidence of disease (10.2 years).

A particularly remarkable finding was cholesteatoma in association with the meningioma in 9 ear and temporal bone cases. This finding was not associated with a high recurrence rate: when a cholesteatoma was present, $22.2 \%$ of patients developed a recurrence versus $29.6 \%$ of patients without a cholesteatoma developed recurrent tumor.

\section{Immunohistochemistry}

Immunohistochemical stains showed strong and diffuse vimentin immunoreactivity in all tumor cells in all cases tested $(n=78)$ (Table 5). Epithelial membrane antigen (EMA) was identified in 61 of 80 cases tested, but the immunoreactivity was focal and generally weak (Fig. 2), accenting only a few cells here and there, rather than yielding a strong and diffuse immunoreactivity. Other epithelial markers were also positive, including keratin (AE1/AE3, CK1 cocktail) in 24\%, CK7 in $21.8 \%$, CAM5.2 in $5.6 \%$, and CK20 in $1.9 \%$. The immunoreactivity was in selected cells and was a focal finding. Particularly noticeable, was a "pre-psammoma" like immunoreactivity with CK7. This stain highlighted the periphery of concretions in a tight, concentric whorl, suggesting a pre-psammoma body like deposition. S-100 protein stained the cytoplasm

Table 5 Immunohistochemical profile of extracranial meningiomas

\begin{tabular}{lc}
\hline Antibody & $\begin{array}{l}\text { Number of cases } \\
\text { with positive reactions }\end{array}$ \\
\hline Vimentin & $78 / 78(100 \%)$ \\
Epithelial membrane antigen (EMA) & $61 / 80(76.3 \%)$ \\
Cytokeratin (AE1/AE3 and CK1) & $18 / 75(24.0 \%)$ \\
CK7 & $12 / 55(21.8 \%)$ \\
S-100 protein & $15 / 78(19.2 \%)$ \\
CAM5.2 & $3 / 54(5.6 \%)$ \\
Synaptophysin & $3 / 75(4.0 \%)$ \\
CK20 & $1 / 52(1.9 \%)$ \\
GFAP & $1 / 69(1.4 \%)$ \\
Chromogranin & $0 / 72(0 \%)$ \\
Synuclein & $0 / 18(0 \%)$ \\
Ki-67 index $(>1 \%)$ & $21 / 78(26.9 \%)$ \\
\hline
\end{tabular}

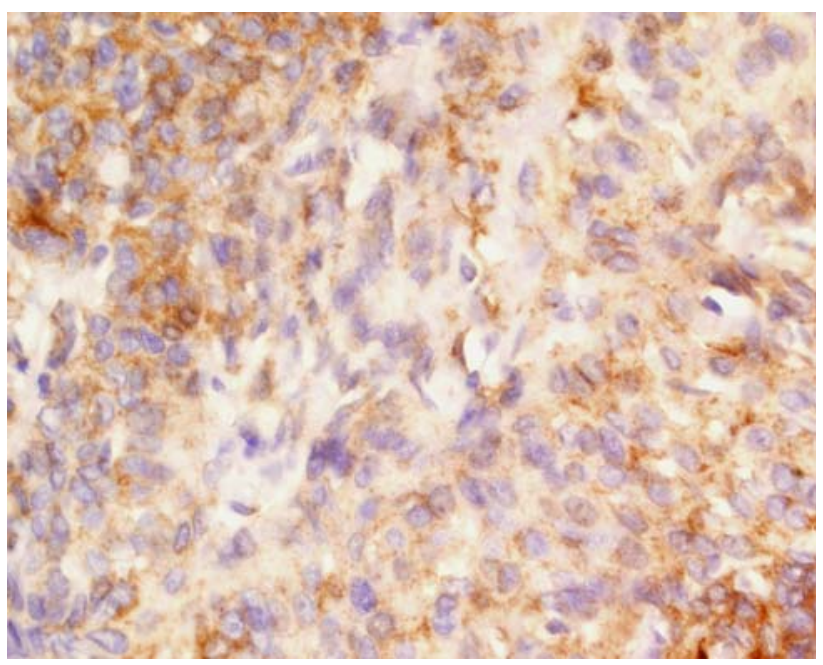

Fig. 2 Immunostaining with epithelial membrane antigen labels the meningothelial cells

and nucleus of a few tumor cells in $19.2 \%$ of cases. Synaptophysin (4\%) and GFAP (1.4\%) were uncommon findings. Chromogranin was not reactive. Isolated tumor cells showed nuclear labelling with $\mathrm{Ki}-67$, although only 14 cases showed increased labelling of $>4 \%$ (of the 78 cases tested). These cases included all of the anaplastic meningiomas, 2 of the atypical meningiomas, and 8 meningothelial meningiomas. Four of the meningothelial meningiomas did not show mitotic figures on hematoxylin and eosin stained material, but the biopsy size was limited and so the proliferation index is probably more reliable. Synuclein was tested in isolated cases $(n=18)$, and was negative in all cases tested.

\section{Treatment and Follow-up}

All patients were treated by partial or complete surgical excision; complete surgical removal of the tumor was frequently impossible to determine for the tumors of the sinonasal tract and ear and temporal bone, while scalp skin and soft tissue lesions were frequently completely removed. Comments about the partial or complete excision were supplied by the operating surgeons, since the fragmentation of the specimen precluded a histologic determination. A few patients were subsequently treated with chemotherapy $(n=1)$, and radiation therapy $(n=5)$, one for recurrent disease. Patient follow-up was available for 110 patients (of the 146 in the study). The following information is set in that context, with percentages based only on the 110 patients in whom follow-up was available.

Overall, the patients were followed for an average of 14.5 years, with a range of 0.1 up to 32.1 years (Table 6). The majority of patients $(n=97)$ were alive $(n=62)$ or had died $(n=35)$ of unrelated causes, yielding a raw 
disease-specific survival of $88.2 \%$. Fifteen patients had evidence of disease at last follow-up: 2 were alive (mean 14.5 years), and 13 had died with disease (mean 6.6 years). It is important to state that these patients died with disease, but not "from" their disease. After accounting for differential lengths of follow-up using the Kaplan-Meier method, median overall survival in this cohort was 28.4 years. Five-year and 10-year survival rates are $79.9 \%$ and $73.1 \%$, respectively. Median disease-specific survival could not be estimated because of the low number of deaths

Table 6 Follow-up, survival and prognostic markers for 110 patients with extracranial meningioma

\begin{tabular}{|c|c|c|c|c|c|c|c|c|c|c|}
\hline & \multirow[b]{2}{*}{$\begin{array}{l}\text { Number of } \\
\text { patients }\end{array}$} & \multirow[b]{2}{*}{$\begin{array}{l}\text { Follow-up } \\
\text { (person-years) }\end{array}$} & \multicolumn{4}{|c|}{ Deaths from all causes } & \multicolumn{4}{|c|}{ Deaths from disease } \\
\hline & & & Deaths & $\begin{array}{l}\text { 5-year } \\
\text { survival }\end{array}$ & $\begin{array}{l}10 \text {-year } \\
\text { survival }\end{array}$ & $P$ value* & Deaths & $\begin{array}{l}\text { 5-year } \\
\text { survival }\end{array}$ & $\begin{array}{l}10 \text {-year } \\
\text { survival }\end{array}$ & $P$ value* \\
\hline All patients & 110 & 1,596 & 48 & 0.799 & 0.731 & & 13 & 0.912 & 0.901 & \\
\hline Recurrence & & & & & & 0.174 & & & & 0.00 \\
\hline No & 84 & 1,263 & 34 & 0.845 & 0.770 & & 2 & 0.988 & 0.988 & \\
\hline Yes & 26 & 333 & 14 & 0.642 & 0.599 & & 11 & 0.674 & 0.629 & \\
\hline Anatomic site & & & & & & 0.155 & & & & 0.763 \\
\hline Ear/temporal bone & 36 & 551 & 10 & 0.833 & 0.772 & & 5 & 0.884 & 0.851 & \\
\hline Sinonasal tract & 33 & 511 & 16 & 0.818 & 0.755 & & 5 & 0.938 & 0.938 & \\
\hline Scalp skin & 33 & 429 & 17 & 0.785 & 0.691 & & 2 & 0.931 & 0.931 & \\
\hline Other & 8 & 104 & 5 & 0.625 & 0.625 & & 1 & 0.857 & 0.857 & \\
\hline Histologic subtype & & & & & & 0.076 & & & & 0.378 \\
\hline Meningothelial & 87 & 1,286 & 37 & 0.815 & 0.728 & & 10 & 0.915 & 0.901 & \\
\hline Psammomatous & 5 & 103 & - & 1.000 & 1.000 & & - & 1.000 & 1.000 & \\
\hline Clear cell & 1 & 11 & - & 1.000 & 1.000 & & - & 1.000 & 1.000 & \\
\hline Atypical & 10 & 121 & 6 & 0.700 & 0.700 & & 1 & 0.875 & 0.875 & \\
\hline Anaplastic & 2 & 14 & 2 & 0.500 & 0.500 & & 1 & 0.500 & 0.500 & \\
\hline Misc & 5 & 62 & 3 & 0.600 & 0.600 & & 1 & 1.000 & 1.000 & \\
\hline Grade & & & & & & 0.052 & & & & 0.133 \\
\hline I & 97 & 1,450 & 40 & 0.813 & 0.736 & & 11 & 0.924 & 0.911 & \\
\hline II & 11 & 132 & 6 & 0.727 & 0.727 & & 1 & 0.889 & 0.889 & \\
\hline III & 2 & 14 & 2 & 0.500 & 0.500 & & 1 & 0.500 & 0.500 & \\
\hline Extent of procedure & & & & & & 0.857 & & & & 0.828 \\
\hline Complete & 100 & 1,447 & 44 & 0.799 & 0.724 & & 12 & 0.913 & 0.901 & \\
\hline Partial & 10 & 149 & 4 & 0.800 & 0.800 & & 1 & 0.900 & 0.900 & \\
\hline Gender & & & & & & 0.974 & & & & 0.017 \\
\hline Female & 58 & 834 & 25 & 0.790 & 0.736 & & 11 & 0.856 & 0.856 & \\
\hline Male & 52 & 762 & 23 & 0.808 & 0.724 & & 2 & 0.981 & 0.956 & \\
\hline Age at diagnosis & & & & & & 0.005 & & & & 0.049 \\
\hline$<40$ years & 41 & 700 & 11 & 0.876 & 0.850 & & 2 & 0.972 & 0.944 & \\
\hline$>40$ years & 69 & 895 & 37 & 0.754 & 0.661 & & 11 & 0.877 & 0.877 & \\
\hline Necrosis & & & & & & 0.010 & & & & 0.009 \\
\hline Absent & 105 & 1,560 & 44 & 0.818 & 0.747 & & 11 & 0.929 & 0.918 & \\
\hline Present & 5 & 36 & 4 & 0.400 & 0.400 & & 2 & 0.500 & 0.500 & \\
\hline Proliferation Index & & & & & & 0.047 & & & & 0.101 \\
\hline$<4 \%$ & 43 & 533 & 20 & 0.670 & 0.622 & & 5 & 0.891 & 0.859 & \\
\hline$\geq 4 \%$ & 11 & 114 & 7 & 0.727 & 0.546 & & 3 & 0.727 & 0.727 & \\
\hline Unknown & 56 & 949 & 21 & 0.911 & 0.853 & & 5 & 0.963 & 0.963 & \\
\hline Cholesteatoma & & & & & & 0.125 & & & & 0.925 \\
\hline Yes & 9 & 126 & 1 & 0.889 & 0.889 & & 1 & 0.889 & 0.889 & \\
\hline No & 101 & 1,470 & 47 & 0.791 & 0.718 & & 12 & 0.915 & 0.903 & \\
\hline
\end{tabular}

* $P$ value from $\log$ rank test 
due to disease. However, disease specific survival rates for specific time points are: $91.2 \%$ at 5 years, $90.1 \%$ at 10 years, $90.1 \%$ at 15 years, $86.2 \%$ at 20 years, $86.2 \%$ at 25 years, and $75.4 \%$ at 30 years. These findings show that while a few patients die of their disease soon after discovery, the majority of patients survive a long time with death resulting from other causes rather than from tumor. However, the continued progression of the disease for decades indicates that long term clinical follow-up is required to monitor disease progression or recurrence.

Twenty-six patients developed a recurrence. Recurrences found within a few months of the initial surgery probably represent residual disease after incomplete excision of the primary rather than representing true recurrence. Recurrences develop in the same site and on the same side as the previous tumor, often yielding a slightly more "infiltrative" pattern than the initial specimen. Tumors which extend into the base of the skull (ear/temporal bone and sinonasal tract tumors) tend to be very difficult to eradicate surgically, and tend to remain indolent for many years. While overall patients with recurrences experienced a good survival (median, 15.6 years), $42.3 \%$ of these patients died of their disease, $32.6 \%$ within 5 years of initial diagnosis. This contrasts with only $1.2 \%$ of patients without recurrences dying of disease within 5 years of diagnosis $(P<0.001)$. Overall survival was lower among patients with recurrences but this difference was not statistically significant (median 31.4 years among patients without recurrence versus 15.6 years among patients with recurrences, $P=0.174$ ). Recurrence appears to increase the risk of dying from disease.

The specific anatomic site of tumor development suggests that 5-year disease-specific survival is slightly higher among patients with scalp skin based tumors (93.1\%) and tumors of the sinonasal tract $(93.8 \%)$ in comparison to tumors of other soft tissue sites $(85.7 \%)$ and ear and temporal bone (88.4\%). However, as there are only a few cases within each group, a statistically significant result could not be measured $(P=0.763)$.

The histologic type does seem to correlate with dying from disease $(P=0.0378)$, although this finding could not be controlled for recurrence specifically. There were no deaths from disease among the 6 patients with psammomatous or clear cell type tumors; ten among the 87 patients with meningothelial meningiomas (5-year survival 91.5\%); and 1 among the ten patients with atypical tumors (5-year survival $87.5 \%$ ). Although five-year survival was only $50 \%$ among patients with anaplastic tumors, this represents one death from disease among two patients.

As would be expected, a greater percentage of patients die from their disease as the grade of the tumor increases. Fiveyear disease specific survival decreases from $92.4 \%$ (Grade I) to $88.9 \%$ (Grade II) to only $50 \%$ (Grade III). Further, it can be seen that the overall duration of survival also decreases as the grade of tumor increases. However, because only 13 patients had Grade II or III tumors, these differences did not reach statistical significance $(P=0.052$ for overall survival; $P=0.133$ for disease-specific survival).

Data about the completeness of the excision is difficult to comment on, as this is not a parameter which can be easily assessed nor confirmed. Therefore, while it may seem that the survival is shorter for patients with a partial removal, with only a single death from disease in this group, it makes a meaningful interpretation difficult.

Based on the data in this study, the overall 5-year survival for males and females is not different: females, $79.0 \%$; males, $80.8 \%, P=0.974$. However, $14.4 \%$ of women died from their disease within 5 years of diagnosis, while only $1.9 \%$ of men died of their disease. This information suggests that female patients have an overall worse prognosis in comparison to male patients $(P=0.017)$.

It is difficult to define outcome based on age, but using a 40 year age cut-off, there is a statistically significant difference in patient outcome and length of survival. Two of 41 patients diagnosed before age 40 died of disease (5-year survival $97.2 \%$ ), compared with 11 of 69 patients diagnosed after age 40 (5-year survival $87.7 \%, P=0.049$ ). Overall survival was also greater among younger patients $(P=0.005)$, indicating that age may be an important prognostic factor. It goes without saying that patients with necrosis $(n=5)$, tend to survive for a shorter period. Four of the 5 patients with necrosis died during the study (5-year survival $40.0 \%$ ), two from their disease (5-year diseasespecific survival $50 \%$ ). These data indicate a poor prognosis for patients with necrosis when compared with other patients (overall 5-year survival 81.8\%, $P=0.010$; 5-year disease-specific survival 92.9\%, $P=0.009$ ).

Overall survival is similar for patients with and without an increased proliferation index during the first 5 years after diagnosis. Five year overall survival is $66.9 \%$ among those with a proliferation index $<4$, compared with $72.7 \%$ among those with a proliferation index $\geq 4$. However, patients with an increased proliferation index $(>4)$ have higher death rates overall, with median survival of only 10.2 years compared to 31.4 among those with proliferation index $<4$, and 10-year survival of $54.6 \%$ compared with $62.2 \%$ among those with proliferation index $<4$ $(P=0.047)$. Disease-specific survival was also lower among those with an increased proliferation index, but this difference did not reach statistical significance.

There are no significant differences between patients who have cholesteatoma and patients who do not have cholesteatoma with respect to all-cause survival $(P=0.125)$ or disease-specific survival $(0.925)$.

A final comment regarding patient management and outcome: the anatomic sites of the head and neck, 
especially the ear and temporal bone, nasal cavity, paranasal sinuses, and even the scalp skin can result in disruption of the adjacent tissues. A number of patients developed mastoiditis, sinusitis, or scalp abscesses. These complications resulted in seeding to the peripheral blood to cause systemic sepsis, which resulted in the patient's death. Therefore, in these patients, even though they may not have residual tumor, the deaths are a direct result of the management for the tumor. Therefore, it is important to consider the inherent risks of surgeries in these vital structures.

\section{Clinicopathologic Correlations}

In summary, older patients, patients with necrosis, and patients with increased proliferation index had significantly reduced overall survival. Women, patients older than 40 years at diagnosis, and patients with recurrence or necrosis were significantly more likely to die of disease $(P<0.05 \log$ rank test; Table 6$)$. When all potential prognostic factors were evaluated jointly using Cox proportional hazards regression, the only independent predictor of overall survival was age group; when non-significant variables were removed sequentially from the model, the remaining significant prognostic factors were age group, anatomical site and presence of necrosis (Table 7). Mortality was more than three times higher among patients whose age was greater than 40 years than among those younger than 40 years at diagnosis (hazard ratio 3.6, 95\% confidence interval 1.8-8.0). We had hypothesized that grade would be a stronger predictor of survival than either

Table 7 Estimated hazard ratios, Cox proportional hazards models

\begin{tabular}{|c|c|c|c|c|c|c|}
\hline \multirow{2}{*}{$\begin{array}{l}\text { Prognostic factor } \\
\text { All-cause mortality }\end{array}$} & \multicolumn{3}{|l|}{ Full model } & \multicolumn{3}{|c|}{ Reduced model ${ }^{* *}$} \\
\hline & Hazard ratio & $95 \% \mathrm{CI}^{*}$ & $P$ & Hazard ratio & $95 \% \mathrm{CI}^{*}$ & $P$ \\
\hline Recurrence & 1.43 & $0.72-282$ & 0.31 & & & \\
\hline Site (vs. Ear) & & & 0.20 & & & 0.02 \\
\hline Nasal & 2.63 & $1.02-6.78$ & 0.04 & 2.09 & $0.93-4.70$ & 0.07 \\
\hline Skin scalp & 1.78 & $0.66-4.81$ & 0.25 & 3.12 & $1.36-7.19$ & 0.01 \\
\hline Other & 2.40 & $0.59-9.78$ & 0.22 & 4.43 & $1.47-31.34$ & 0.01 \\
\hline Grade II or III & 0.81 & $0.22-3.00$ & 0.76 & & & \\
\hline Male & 1.24 & $0.63-2.44$ & 0.54 & & & \\
\hline Age $>40$ & 3.79 & $1.80-8.00$ & 0.00 & 3.53 & $1.74-7.15$ & 0.00 \\
\hline Necrosis & 3.44 & $0.70-16.81$ & 0.13 & 2.84 & $0.97-8.34$ & 0.06 \\
\hline Cholesteatoma & 0.42 & $0.05-3.39$ & 0.42 & & & \\
\hline PI & & & 0.12 & & & \\
\hline $\mathrm{PI}>4 \%$ & 0.78 & $0.24-2.51$ & 0.68 & & & \\
\hline Unknown PI & 0.38 & $0.15-0.95$ & 0.04 & & & \\
\hline \multicolumn{7}{|c|}{ Disease-specific mortality } \\
\hline Recurrence & 19.04 & $3.48-104.3$ & 0.00 & 26.00 & $5.13-131.8$ & 0.00 \\
\hline Site (vs. Ear) & & & 0.21 & & & 0.08 \\
\hline Nasal & 6.29 & $0.64-62.05$ & 0.12 & 7.69 & $0.78-75.96$ & 0.08 \\
\hline Skin scalp & 0.32 & $0.03-3.46$ & 0.35 & 0.38 & $0.07-2.08$ & 0.26 \\
\hline Other & 0.31 & $0.02-4.24$ & 0.38 & 0.14 & $0.01-1.66$ & 0.12 \\
\hline Male & 0.46 & $0.08-2.80$ & 0.40 & & & \\
\hline Age $>40$ & 1.40 & $0.20-9.84$ & 0.74 & & & \\
\hline Necrosis & 3.03 & $0.32-28.47$ & 0.33 & & & \\
\hline Cholesteatoma & 1.06 & $0.11-10.02$ & 0.96 & & & \\
\hline PI & & & 0.05 & & & 0.01 \\
\hline $\mathrm{PI}>4 \%$ & 3.03 & $0.39-23.52$ & 0.29 & 5.05 & $0.95-26.80$ & 0.06 \\
\hline Unknown PI & 0.09 & $0.01-0.94$ & 0.04 & 0.08 & $0.01-0.85$ & 0.04 \\
\hline
\end{tabular}

* CI confidence interval

** Variables in the reduced model were selected from among the variables in the full model using the backwards stepwise variable selection algorithm implemented in SPSS version 14. Variables with $P<0.10$ were retained in the final model 
necrosis or proliferation index because both of these variables are part of the grading criteria. However, at least in this population, necrosis is a better predictor of all-cause mortality than either grade or proliferation index.

The best predictor of disease-specific survival was recurrence. Adjusting for other prognostic factors, the estimated hazard ratio associated with recurrence is 19 (95\% confidence interval 3.5-104.3). After adjusting for recurrence, gender, age and necrosis were no longer statistically significant, perhaps because women and patients with necrosis were twice as likely as other patients to experience recurrence. Patients with proliferation index of $4 \%$ or higher were three times more likely to die of disease than patients with proliferation index below $4 \%$, although given the small number of patients this did not reach statistical significance. Patients with unknown proliferation index were $90 \%$ less likely to die of disease. When nonsignificant variables were removed from the regression model sequentially, differences among sites reached statistical significance. Compared with tumors of the ear, the estimated risk of dying of disease was more than 7 times higher for patients with nasal tumors, and more than $60 \%$ lower for patients with skin scalp tumors.

\section{Discussion}

Arachnoid cells (arachnoid granulations, meningiocytes, meningothelial cells, pacchionian bodies) are thought to arise from neural crest. They normally line the inner aspect of the arachnoid membrane, and fill the cores of the arachnoid villi that project into the lumens of dural veins and venous sinuses. Increasing evidence supports the development of meningiomas from arachnoid cap cells, with different mechanisms to suggest how extracranial meningiomas arise:

(1) Arachnoidal cells are present in the sheaths of nerves or vessels where they emerge through the skull foramina.

(2) Displaced pacchionian bodies become detached, pinched off, or entrapped during embryologic development in an extracranial location.

(3) A traumatic event or cerebral hypertension that displaces arachnoid islets.

(4) An origin from undifferentiated or multipotential mesenchymal cells, such as fibroblasts, Schwann cells, or a combination of these, perhaps explaining the diverse pathologic spectrum found in meningiomas. Consequently, by one mechanism or another, arachnoid cells are identified outside the neuraxis and give rise to meningiomas in extracranial locations, including ear, sinonasal tract, scalp and soft tissues $[3,8,10,14,19-21,25-39]$.
Up to $20 \%$ of intracranial meningiomas may have extraneuraxial extension [10,14, 19-21, 25-42], including the skull, scalp (all cutaneous sites), orbit, upper airway involvement (nasal cavity, paranasal sinuses, nasopharynx), soft tissues, and ear and temporal bone. However, when the scalp, orbit, sinonasal tract, oral cavity, and soft tissues are excluded, the incidence decreases to less than $1 \%[19-21,25,27,37,38,40,43-45]$. Based on our findings, we believe the majority of our cases are arising de novo from multipotential stem cell, although a number of the cases within the ear and temporal bone and sinonasal tract may develop from misplaced remnants of the pacchionian bodies. While there are a number of reported cases of "ectopic" or "heterotopic" meningiomas, most of these were reported prior to the modern improvement in radiographic techniques which serves to more definitively exclude intracranial disease. It is important to exclude an intracranial component radiographically or during surgery to yield the best possible management and follow-up. The possibility of an intracranial tumor must always be considered if long term management is to achieve its intended goal $[8,10,19,20,34,46]$.

Both genders were equally affected in this clinical series in the aggregate (74 females and 72 males), although ear and temporal bone tumors were more common in females than males (2:1) and males were more commonly affected than females for skin scalp lesions (1.7:1). This is in contrast to the reported predilection of intracranial tumors for females [1].

Females tend to be significantly older (mean 45.6 years) than males (mean 39.6 years, $P=0.01$ ), with the exception of soft tissue tumors where males tend to be older (mean 42 years) than females (mean 31 years). Further, patients with tumors of the skin scalp tend to present at a younger mean age (36.2 years) than tumors which develop in the ear and temporal bone (mean 50.1 years) and sinonasal tract (mean 47.1 years). This may be due to a greater facility for clinical identification of a skin scalp lesion rather than an inner ear or sinonasal tract tumor. The overall average age at presentation of our patients (42.4 years) is not dissimilar from the middle-aged figure used for intracranial meningiomas without any extracranial extension. No patients in this clinical series had any syndrome-associated meningiomas.

Meningothelial meningiomas are the most common tumor type identified in this clinical series. Interestingly, $95 \%$ of ear and temporal bone lesions were meningothelial, but only $43 \%$ of soft tissue sites showed this pattern. This suggests that a greater degree of vigilance is required to render this diagnosis when looking at tumors in such unusual anatomic sites as the parotid gland, Achilles tendon or the pelvis. Nearly one-third of meningiomas in the soft tissues are atypical, further emphasizing the need for 
careful consideration of this diagnosis in unusual locations. Atypical meningiomas [1, 22, 47] were diagnosed in 11 cases in this series. The soft tissue sites, including the neck and pelvis, were most commonly affected, but the sinonasal tract and scalp skin were also affected by a few tumors each. Interestingly, atypical histology did not portend a worse outcome for these extracranial sites as it may for intracranial lesions $[19,20,24]$. It may be they are discovered at an early stage of development, allowing for earlier surgery than their intracranial counterparts.

Axiomatic, the immunohistochemical profile of extracranial meningiomas is indistinguishable from intracranial lesions; therefore, no ancillary technique can separate direct extension from ectopic/extracranial meningioma. Surprisingly, staining for CK7 was detected in $21.8 \%$ of cases. Expression of CK7 in meningiomas has been previously reported $[19,20]$, specifically in secretory meningioma [7]. In our series, expression was localized to prepsammoma bodies, similar to those observed in secretory meningiomas, but secretions were not seen in any of the cases in this series. Therefore, it may be that the specific CK7 staining pattern may help with yielding a diagnosis of meningioma in these extracranial sites.

When receiving these cases in consultation, $24 \%$ of the cases were incorrectly diagnosed, with a larger proportion submitted as "undetermined." This results in inadequate or inappropriate management, especially if an intracranial primary has not been excluded. The differential diagnosis of extracranial meningiomas includes a variety of benign and malignant neoplasms dependent upon the anatomic site of involvement. Paraganglioma, schwannoma and metastatic carcinomas are the most frequent misdiagnoses for ear and temporal bone tumors [3, 19, 48]; carcinoma, melanoma, olfactory neuroblastoma, and aggressive psammomatoid ossifying fibroma for sinonasal tract lesions [6, 20, 49-51]; dermatofibroma, melanoma, fibrosarcoma, leiomyosarcoma, and synovial sarcoma for soft tissue and skin lesions, especially for Grade II or III tumors, and for the non-meningothelial types of meningiomas.

The general histologic features and immunohistochemical findings can usually separate between these tumors $[3,6,9]$. Specifically, paraganglioma will show more of a nested, Zellballen pattern, with granular cytoplasm and chromogranin, synaptophysin, CD56, and S-100 protein immunoreactivity (highlighting their respective compartments). Schwannoma will demonstrate different degrees of cellularity, with areas of myxoid change, perivascular hyalinization, wavy nuclei, and strong, diffuse S-100 protein immunoreactivity. Metastatic carcinomas or carcinoma in general tends to show more pleomorphism, a much higher mitotic rate, and will be immunoreactive with a variety of keratins. Whereas psammoma bodies can be seen in papillary carcinomas (thyroid, lung, ovary), the growth pattern of meningioma tends not to be papillary in these extracranial sites. Melanoma (cutaneous or mucosal) can mimic any tumor type, replete with intranuclear cytoplasmic inclusions and whorled architecture. However, pigment, prominent, irregular nucleoli, and melanocytic markers (including S-100 protein, HMB-45, melan-A, MART1, tyrosinase, microphthalmia transcription factor) will help to make the distinction. Olfactory neuroblastoma occurs with direct proximity to the cribriform plate region, usually maintains a lobular growth pattern of small to intermediate cells with scant cytoplasm, has a fibrillary background, exhibits rosette and/or pseudorosette formations, and displays characteristic immunohistochemical features (chromogranin, synaptophysin, neuron specific enolase and CD56 tumor cell staining and S-100 protein sustentacular staining) that are easy to separate from meningiomas. An aggressive psammomatoid ossifying fibroma is an uncommon lesion which may be confused with meningioma because both lesions occur in young to middle-aged patients and may be associated with proptosis. Both lesions have abundant psammoma bodies, but meningiomas lack associated osteoclasts and osteoblasts. Furthermore, the background stromal pattern is storiform and more compact than a meningioma and does not have the same immunophenotypic characteristics as a meningioma. High grade tumors with pleomorphism, necrosis, and increased mitotic activity with a loss of architecture, may be very difficult to separate from skin or soft tissue sarcomas. Usually, small foci of recognizable meningioma will be present, showing a vague whorling pattern. The weak EMA may help, although EMA will be reactive in synovial sarcoma. Specific sarcomas will generally exhibit specific histologic, immunophenotypic or molecular results that allow for their categorization apart from meningioma.

In general, the prognosis of extracranial meningiomas appears to be excellent, with an overall median survival of 28 years. This is tempered by the specific anatomic site, histologic type, tumor grade, gender, and age of the patient. The recurrence rate for meningiomas after total excision varies from $7 \%$ to $84 \%$ depending upon the number of years of follow-up [13, 19, 22, 25, 47, 52, 53], with our rate of $23.6 \%$ falling within this range. This is similar to intracranial meningiomas which have a recurrence rate of up to $20 \%$ and a mean survival around 7 years $[1,25,52]$.

In this study, there was little difference between the 5 and 10-year disease-free survival rates $(91.2 \%$ versus $90.1 \%$, respectively), indicating that once the patients survived disease free for 5 years, they were unlikely to die with tumor. Furthermore, this same trend was noted at 15, 20,25 and 30 years $(90.1 \%, 86.2 \%, 86.2 \%$, and $75.4 \%$, respectively). Nine of the thirteen patients who died of their disease, died within the first 5 years. The remaining four patients died at 5.9, 15.6, 17.3, and 28.4 years, 
respectively. One patient was still alive with local disease at 27.5 years. This finding supports the slow, indolent growth of extracranial meningiomas, but also suggests very long term clinical follow-up is necessary to achieve these outcomes. Our findings are different from meningiomas in general in which the recurrence rate increases with protracted follow-up (6\% recurrence at 5 years and $20 \%$ recurrence at 15 years [52]). Therefore, meticulous surgical extirpation of extracranial meningiomas is important to minimize the recurrence rate, without the necessity of adjuvant therapy. While surgery is the treatment of choice, there are a number of challenges due to the invasiveness of the tumors and the complexity of the anatomy within the sinonasal tract and ear and temporal bone, although scalp and soft tissues lesions are no less difficult to remove if they are adjacent to vital structures. It may be necessary to utilize a multidisciplinary approach with a combination of intracranial, temporal bone, maxillofacial, and skull base techniques to achieve total resection, possibly including widely exenterative procedures to achieve this end $[10,16$, 29, 31, 37, 54-61].

Five patients received radiation in this series. Radiation therapy has been suggested to yield a possible improvement in survival in meningiomas of the central nervous system [13, 53, 57, 62]. However, this does not seem to be the case in this series, although the numbers are limited: One patient with recurrence, died of disease ( 0.5 years); three patients are alive without evidence of disease (mean 14.2 years), and one patient died without evidence of disease (15.6 years). Further evaluation may be necessary in a larger group of patients.

In our cases, and in those of the literature, when recurrences developed, they usually arise in the same anatomic site as the primary lesion and depending on time interval, may represent residual disease rather than recurrent tumor. Metastatic disease did not occur in any of our patients nor did we find any convincing cases in the literature of extracranial meningiomas resulting in metastasis.

Meningiomas that arise outside the skull are for the most part benign tumors. Symptoms are associated with the location of the lesion. Imaging studies may provide some suspicion of diagnosis, but confirmation relies on pathologic examination. The mainstay of treatment is complete excision of the tumor by appropriate approaches, often requiring multidisciplinary approach. The histologic features, while generally "characteristic", especially for meningothelial tumors, may be atypical, requiring separation from other tumor types, by both histologic and immunohistochemistry studies. Separation from other tumors is essential as extracranial meningioma seems to have an excellent long term prognosis with only limited recurrence.
Acknowledgments The opinions or assertions contained herein are the private views of the authors and are not to be construed as official or as reflecting the views of the Department of Army, Department of the Air Force, or the Department of Defense.

Open Access This article is distributed under the terms of the Creative Commons Attribution Noncommercial License which permits any noncommercial use, distribution, and reproduction in any medium, provided the original author(s) and source are credited.

\section{References}

1. Louis DN, Ohgaki H, Wiestler OD, Cavenee WK. World Health Organization classification of tumours of the central nervous system. 4th ed. Lyon: IARC Press; 2007.

2. Nichols RD, Knighton RS, Chason JL, Strong DD. Meningioma in the parotid region. Laryngoscope. 1987;97:693-6. doi: 10.1288/00005537-198706000-00008.

3. Chang CY, Cheung SW, Jackler RK. Meningiomas presenting in the temporal bone: the pathways of spread from an intracranial site of origin. Otolaryngol Head Neck Surg. 1998;119:658-64. doi:10.1016/S0194-5998(98)70030-0.

4. Galm T, MacGregor F, Sinclair AM, Hunter J, McPhaden A. Extracranial meningioma presenting as a neck mass in a patient with underlying ankylosing spondylitis. J Rheumatol. 2006;33: 1883-5.

5. Gilbert ME, Shelton C, McDonald A, Salzman KL, Harnsberger HR, Sharma PK, et al. Intraventricular meninigiomas: a report of 25 cases. Neurosurg Rev. 2006;29:36-40. doi:10.1007/s10143005-0418-1.

6. Agrawal A, Rao KS, Makannavar JH, Shetty L, Patel N. Extracranial meningioma in the vicinity of the temporal bone: a difficult preoperative diagnosis. Surg Neurol. 2007;67:102-5. doi: 10.1016/j.surneu.2006.02.043.

7. Assi A, Declich P, Iacobellis M, Cozzi L, Tonnarelli G. Secretory meningioma, a rare meningioma subtype with characteristic glandular differentiation: an histological and immunohistochemical study of 9 cases. Adv Clin Path. 1999;3:47-53.

8. Batsakis JG. Pathology consultation. Extracranial meningiomas. Ann Otol Rhinol Laryngol. 1984;93:282-3.

9. Ferlito A, Devaney KO, Rinaldo A. Primary extracranial meningioma in the vicinity of the temporal bone: a benign lesion which is rarely recognized clinically. Acta Otolaryngol. 2004;124:5-7. doi:10.1080/00016480310014903.

10. Friedman CD, Costantino PD, Teitelbaum B, Berktold RE, Sisson GA Sr. Primary extracranial meningiomas of the head and neck. Laryngoscope. 1990;100:41-8.

11. Gagnon NB, Lavigne F, Mohr G, Guerard MJ, Bouvier G. Extracranial and intracranial meningiomas. J Otolaryngol. $1986 ; 15: 380-4$.

12. Liu Y, Sturgis CD, Bunker M, Saad RS, Tung M, Raab SS, et al. Expression of cytokeratin by malignant meningiomas: diagnostic pitfall of cytokeratin to separate malignant meningiomas from metastatic carcinoma. Mod Pathol. 2004;17:1129-33. doi: 10.1038/modpathol.3800162.

13. Maniglia AJ. Intra and extracranial meningiomas involving the temporal bone. Laryngoscope. 1978;88:1-58.

14. Nager GT, Heroy J, Hoeplinger M. Meningiomas invading the temporal bone with extension to the neck. Am J Otolaryngol. 1983;4:297-324. doi:10.1016/S0196-0709(83)80018-0.

15. Nur S, Chuang L, Ramaswamy G. Primary extracranial meningioma of the pelvis: a light microscopic, immunohistochemical, 
and ultrastructural study. Gynecol Oncol. 2006;103:745-8. doi: 10.1016/j.ygyno.2006.05.050.

16. Petrulionis M, Valeviciene N, Paulauskiene I, Bruzaite J. Primary extracranial meningioma of the sinonasal tract. Acta Radiol. 2005;46:415-8. doi:10.1080/02841850510021210.

17. Perzin KH, Pushparaj N. Nonepithelial tumors of the nasal cavity, paranasal sinuses, and nasopharynx. A clinicopathologic study. XIII: meningiomas. Cancer. 1984;54:1860-9. doi:10.1002/1097 0142(19841101)54:9<1860::AID-CNCR2820540916>3.0.CO;2-9.

18. Pfeifer JD, Ashley HD, Ramos CV, Wippold FJ II, Dehner LP. Meningioma presenting as an intraoral mass in a patient with neurofibromatosis type 1. Arch Pathol Lab Med. 2000;124:898901.

19. Thompson LD, Bouffard JP, Sandberg GD, Mena H. Primary ear and temporal bone meningiomas: a clinicopathologic study of 36 cases with a review of the literature. Mod Pathol. 2003;16:23645. doi:10.1097/01.MP.0000056631.15739.1B.

20. Thompson LD, Gyure KA. Extracranial sinonasal tract meningiomas: a clinicopathologic study of 30 cases with a review of the literature. Am J Surg Pathol. 2000;24:640-50. doi:10.1097/ 00000478-200005000-00002.

21. Miyamoto T, Mihara M, Hagari Y, Shimao S. Primary cutaneous meningioma on the scalp: report of two siblings. J Dermatol. 1995;22:611-9.

22. De la Monte SM, Flickinger J, Linggood RM. Histopathologic features predicting recurrence of meningiomas following subtotal resection. Am J Surg Pathol. 1986;10:836-43. doi:10.1097/ 00000478-198612000-00002.

23. Perry A, Stafford SL, Scheithauer BW, Suman VJ, Lohse CM. Meningioma grading. An analysis of histologic parameters. Am J Surg Pathol. 1997;21:1455-65. doi:10.1097/00000478199712000-00008.

24. Perry A, Scheithauer BW, Stafford SL, Lohse CM, Wollan PC. "Malignancy" in meningiomas: a clinicopathologic study of 116 patients, with grading implications. Cancer. 1999;85:2046-56.

25. Civantos F, Ferguson LR, Hemmati M, Gruber B. Temporal meningiomas presenting as chronic otitis media. Am J Otol. 1993;14:403-6.

26. Bain GO, Shnitka TK. Cutaneous meningioma (psammoma). Report of a case. Arch Dermatol. 1956;74:590-4.

27. Farr HW, Gray GF Jr, Vrana M, Panio M. Extracranial meningioma. J Surg Oncol. 1973;5:411-20. doi:10.1002/jso.2930050503.

28. Guzowski J, Paparella MM, Nageswara K, Hoshino T. Meningiomas of the temporal bone. Laryngoscope. 1976;86:1141-6. doi:10.1288/00005537-197608000-00006.

29. Hooper R, Siu K, Cousins V. Temporal bone meningiomas. Aust N Z J Surg. 1990;60:779-86. doi:10.1111/j.1445-2197.1990. tb07473.x.

30. Hoye SJ, Hoar CS Jr, Murray JE. Extracranial meningioma presenting as a tumor of the neck. Am J Surg. 1960;100:486-9. doi: 10.1016/0002-9610(60)90394-9.

31. Langman AW, Jackler RK, Althaus SR. Meningioma of the internal auditory canal. Am J Otol. 1990;11:201-4.

32. Lopez DA, Silvers DN, Helwig EB. Cutaneous meningiomas. A clinicopathologic study. Cancer. 1974;34:728-44. doi:10.1002/ 1097-0142(197409)34:3<728::AID-CNCR2820340332>3.0.CO; 2-U.

33. Ohta S, Yokoyama T, Uemura K, Nishizawa S, Yamamoto S, Hoshino T. Petrous bone meningioma originating from the jugular foramen—case report. Neurol Med Chir (Tokyo). 1997; 37:472-4. doi:10.2176/nmc.37.472.

34. Rietz DR, Ford CN, Kurtycz DF, Brandenburg JH, Hafez GR. Significance of apparent intratympanic meningiomas. Laryngoscope. 1983;93:1397-404. doi:10.1288/00005537-198311000-00002.

35. Shuangshoti S, Panyathanya R. Ectopic meningiomas. Arch Otolaryngol. 1973;98:102-5.
36. Siegel GJ, Anderson PJ. Extracalvarial meningioma. Case report. J Neurosurg. 1966;25:83-6.

37. Simpson MT, Sneddon KJ. Extracranial meningioma of the oral cavity. Br J Oral Maxillofac Surg. 1987;25:520-5. doi:10.1016/ 0266-4356(87)90146-X.

38. Waga S, Nishikawa M, Ohtsubo K, Kamijyo Y, Handa H. Extracalvarial meningiomas (2 cases). Neurology. 1970;20:368-72.

39. Wolff M, Randow RM. Meningioma of the parotid gland. An insight into the pathogenesis of extracranial meningioma. Hum Pathol. 1971;2:453-9. doi:10.1016/S0046-8177(71)80010-2.

40. Whicker JH, Devine KD, MacCarty CS. Diagnostic and therapeutic problems in extracranial meningiomas. Am J Surg. 1973;126:452-7. doi:10.1016/S0002-9610(73)80029-7.

41. Brookler KH, Hoffman RA, Camins M, Terzakis J. Trilobed meningioma: ampulla of posterior semicircular canal, internal auditory canal, and cerebellopontine angle. Am J Otol. 1980;1:171-3.

42. Buehrle R, Goodman WS, Wortzman G. Meningioma of the temporal bone. Can J Otolaryngol. 1972;1:16-20.

43. Wolman L. The extracranial spread of meningioma. Eye Ear Nose Throat Digest. 1969;46-57.

44. Brown AM, Fordham KC, Lally ET. Meningioma presenting as an intraoral mass. Oral Surg Oral Med Oral Pathol. 1976;41:7716. doi:10.1016/0030-4220(76)90191-2.

45. Granich MS, Pilch BZ, Goodman ML. Meningiomas presenting in the paranasal sinuses and temporal bone. Head Neck Surg. 1983;5:319-28. doi:10.1002/hed.2890050407.

46. Rosencrantz M, Stattin S. Extradural meningiomas. Report of two cases. Acta Radiol Diagn (Stockh). 1972;12:419-27.

47. Cerdá-Nicolás M, López-Ginés C, Peydró-Olaya A, Barcia-Salorio JL, Llombart-Bosch A. Histologic and cytogenetic patterns in benign, atypical, and malignant meningiomas. Does correlation with recurrence exist? Int J Surg Pathol. 1995;2:301-10. doi: 10.1177/106689699500200407.

48. Torske KR, Thompson LD. Adenoma versus carcinoid tumor of the middle ear: a study of 48 cases and review of the literature. Mod Pathol. 2002;15:543-55. doi:10.1038/modpathol.3880561.

49. Johnson LC, Yousefi M, Vinh TN, Heffner DK, Hyams VJ, Hartman KS. Juvenile active ossifying fibroma. Its nature, dynamics and origin. Acta Otolaryngol Suppl. 1991;488:1-40.

50. Wenig BM, Vinh TN, Smirniotopoulos JG, Folwer CB, Houston GD, Heffner DK. Aggressive psammomatoid ossifying fibromas of the sinonasal region. A clinicopathologic study of a distinct group of fibro-osseous lesions. Cancer. 1995;76:1155-65. doi: 10.1002/1097-0142(19951001)76:7<1155::AID-CNCR28207607 $10>3.0 . \mathrm{CO} ; 2-\mathrm{P}$.

51. Thompson LDR, Wieneke JA, Miettinen M. Sinonasal tract melanomas: a clinicopathologic study of 115 cases with a proposed staging system. Am J Surg Pathol. 2003;27:594-611. doi: 10.1097/00000478-200305000-00004.

52. Mirimannoff RO, Dosoroetz DE, Linggood RM, Ojemann RG, Martuza RL. Meningioma: analysis of recurrence and progression following neurosurgical resection. J Neurosurg. 1985;62:18-24.

53. Stafford SL, Perry A, Suman VJ, Meyer FB, Scheithauer BW, Lohse CM, et al. Primarily resected meningiomas: outcome and prognostic factors in 581 Mayo Clinic patients, 1978 through 1988. Mayo Clin Proc. 1998;73:936-42. doi:10.4065/73.10.936.

54. Ishikawa N, Komatsuzaki A, Tokano H. Meningioma of the internal auditory canal with extension into the vestibule. J Laryngol Otol. 1999;113:1101-3. doi:10.1017/S0022215100158001.

55. Nassif PS, Shelton C, Arriaga M. Hearing preservation following surgical removal of meningiomas affecting the temporal bone. Laryngoscope. 1992;102:1357-62. doi:10.1288/00005537-19921 2000-00009.

56. Pensak ML, Van Loveren H, Tew JM, Keith RW. Transpetrosal access to meningiomas juxtaposing the temporal bone. Laryngoscope. 1994;104:814-20. 
57. Fujita T, Nakagawa H, Tsuruzono K, Izumoto S, Kadota T, Wada A. Extradural temporal meningioma directly extended to cervical bone-case report. Neurol Med Chir (Tokyo). 1993;33:458-62.

58. Fujitsu K, Saijoh M, Aoki F, Sakata K, Fujii S, Mochimatsu Y, et al. Telecanthal approach for meningiomas in the ethmoid and sphenoid sinuses. Neurosurgery. 1991;28:714-9. doi:10.1097/ 00006123-199105000-00013.

59. Geoffray A, Lee YY, Jing BS, Wallace S. Extracranial meningiomas of the head and neck. AJNR Am J Neuroradiol. 1984;5:599-604.
60. Goffin J, Fossion E, Plets C, Mommaerts M, Vrielinck L. Craniofacial resection for anterior skull base tumours. Acta Neurochir (Wien). 1991;110:33-7.

61. Tekkok IH, Ozcan OE, Turan E, Onol B. Jugular foramen meningioma. Report of a case and review of the literature. J Neurosurg Sci. 1997;41:283-92.

62. Swain RE Jr, Kingdom TT, DelGaudio JM, Muller S, Grist WJ. Meningiomas of the paranasal sinuses. Am J Rhinol. 2001;15:2730. doi:10.2500/105065801781329419. 